\title{
Impacts of m-DPBL Approach towards Computer Networks Teaching and Learning Process
}

\author{
https://doi.org/10.3991/ijet.v13i03.7944 \\ Sri Winarno $(\stackrel{\square}{\square}$ \\ Dian Nuswantoro University, Semarang city, Central Java, Indonesia \\ fattahmg@gmail.com \\ Kalaiarasi Sonai Muthu, Lew Sook Ling \\ Multimedia University, Melaka, Indonesia
}

\begin{abstract}
Multimedia learning helps students understand concepts. Almost all subjects nowadays require multimedia to accomplish their learning objectives, one of them being the Computer Networks course. However, the major population of institutions follows a traditional approach to teaching when it comes to the Computer Networks subject. Abstract concepts and principles are described by the lecturer orally and followed by illustrating some examples using the whiteboard. This situation has decreased students' interest and problemsolving skills. Therefore, innovation of the learning model is imperative for a new development. This study discusses the impacts of multimedia teaching and learning of Computer Networks in the Direct Problem-Based Learning (mDPBL) approach. A quasi-experimental group with pre-test and post-test design was used. Third-year students $(\mathrm{N}=276)$ who took Computer Networks subject from two different departments in Dian Nuswantoro University, Indonesia and five lecturers participated in this study. Two selected instructional approaches; one used direct instruction lecturer approach while the other used the m-DPBL approach. Standardised questionnaires of attitude, interest, and creative thinking, teamwork, and knowledge abilities were administered before and after three weeks. Learning outcomes were significantly positively (Sig. $p=.000)$ in terms of students' attitude, interest (Sig. $p=0.001$ ), and knowledge (Sig. $p=$ $.000)$. There were differences in the mean scores between direct instruction and the m-DPBL approach. Students' attitude mean score increased 2.15 points $(7,8 \%)$, students' interest mean score increased 1.34 points $(4,4 \%)$, and students' knowledge mean score increased 11.22 points $(25,9 \%)$.
\end{abstract}

Keywords-Traditional teaching, multimedia learning, direct problem-based learning

\section{Introduction}

Much of the changes we see are driven by demands for graduates who are able to function in the workplace. Recent studies have pointed out the gaps between the skills that graduates have when they finish school and those required for the workplace, 
especially soft skills. Such studies have shown that skills required in the workplace included creativity, critical-thinking, problem-solving, and communication skills [1], many of which are lacking in today's graduates. According to [2], a major population of institutions follows a direct instruction or traditional approach to teaching. In traditional teaching, students are listeners in the classroom and they are too busy writing down the information presented by the lecturers. The lecturers use verbal communication, whiteboard, and slide presentation in the teaching process. In the classroom, they carry out an explanation for the subject according to the textbook and then write it on the whiteboard. After lecturing, the lecturers will give some assignments to the students. The students' activities in the classroom include listening to the explanation of the teacher, take notes, memorising the subjects and do some assignments. This traditional approach has made the students become stressed and bored, while also decreasing their problem-solving skills [3]. Therefore, reformation and design of the teaching approach are imperative in the new development approach; it has become feasible to integrate multimedia into the teaching and learning process.

Universities today are in education transition. Many universities including those in Indonesia are finding new means to make traditional learning more efficient and effective with multimedia. Multimedia is the materials used by teachers and learners to help them teach effectively. Teaching is influenced by the multimedia, facilitating the students to learn something using various media such as print, television, the Internet, pictures and audio. Multimedia is changing the way we communicate with each other. The way we send and receive messages is more effectively done and better comprehended. The inclusion of media elements reinforces the message and delivery, which leads to a better learning rate. The power of multimedia lies in the fact that it is multisensory; stimulating the many senses of the audience. It is also interactive; enabling the end-users of the application to control the content and flow of information [4]. This has introduced important changes in our educational system and impacted the way we communicate information to the learners [5].

\section{State of the art}

Computer Networks is one of the core subjects for computer science students. Teaching the Computer Networks course to students has always been a challenge for educators since the subject requires more practical understanding than theoretical lectures. "Why is it so difficult to learn Computer Networks?" is perhaps as the question that educators should ask themselves and their students. One of the obvious answers is Computer Networks concepts and protocols are very abstract for many students. For one, they cannot see typical networking equipment and visualise packets and protocols for themselves during lectures [6]. An example is talking about how routers communicate and collaborate to select suitable routing paths along the network. The multimedia learning alleviates the problem to some extent, but it may not be able to equip students with the ability to conceptualise other more abstract concepts on their own. Therefore, in the current teaching, an innovation is required to 
understand the subject because grasping these abstract concepts depends on imagination and visualisation of students in their mind while teaching and learning.

Therefore, this study discusses the impacts of the multimedia teaching and learning for Computer Networks subject in the Direct Problem-Based Learning (m-DPBL) approach in Dian Nuswantoro University, Indonesia.

\section{$3 \quad$ Methodology}

The research was performed in Dian Nuswantoro University, Indonesia. Two departments (i.e. Informatics Engineering and Information System Department) were selected.

\subsection{Design and sample}

A quasi-experimental group with the pre-test and post-test design was used. Thirdyear students $(\mathrm{N}=276)$ who took the Computer Networks subject from two departments in Dian Nuswantoro University in Indonesia were involved. In two selected educational programmes, one used direct instructional approach that consisted of 140 students; while the other used the m-DPBL approach that consisted of 136 students. Five Computer Networks lecturers in the sample class participated in this study.

\subsection{Procedures and instrument}

The protocol was reviewed and ethical permission for the study was received from the university through each department. The m-DPBL and direct instruction approaches were conducted over one semester comprising of 14 weeks. Students in both groups completed a demographic form, and creative thinking, teamwork, and knowledge questionnaires at the same time prior to the direct instruction and m-DPBL lecture instruction. For the m-DPBL group, there were 136 students assigned to $25 \mathrm{~m}$ DPBL groups; each m-DPBL group consisted of five - six students. The m-DPBL group session was two hours per week for three weeks.

\subsection{Pilot study}

A pilot study was conducted on 30 undergraduate students and five lecturers to determine the reliability of the tools. The Cronbach's Alpha coefficient for the questionnaires in the pilot study was 0.797 . In general, the respondents of the pilot study gave positive feedback towards the general structure and presentation of the questionnaire. To improve the face validity of the scales, the survey questionnaire was further refined based on some comments collected from the participants. In order to assess the face and content validity and ensure its adaptability to the local cultural context, the instrument was reviewed and approved by the expert from the Faculty of Computer Sciences, Dian Nuswantoro University, Indonesia. 


\subsection{Data analysis}

Standardised questionnaires of attitude, interest, and creative thinking, teamwork, and knowledge abilities were administered before and after three weeks (after instruction). IBM SPSS statistics 21 was used to analyse the data. Frequency and descriptive and t-test analyses were employed to compare the baseline measurements of the demographic and dependent variables between the two groups, using five criteria for evaluation according to the Likert scale.

\section{4 m-DPBL for teaching and learning development}

The teaching process of Computer Networks in Dian Nuswantoro University, Indonesia was tested using the multimedia teaching and learning in the Direct ProblemBased Learning (m-DPBL) learning situation. Teaching approach was adapted from the Direct Problem-Based Learning (DPBL) approach whereas Armani's model [7] was used as a multimedia teaching and learning model. The multimedia teaching and learning of Computer Networks were integrated into the online learning system (i.e. KULINO = Kuliah Online Universitas Dian Nuswantoro). The various contents concerning routing were described using text, sound, image, and animation in the Indonesian language. Students were provided with content in the form of text and animation that enabled them to explore multimedia teaching and learning more enthusiastically. Some features to aid teaching and learning available in the multimedia teaching and learning of Computer Networks were as follows:

Fig. 1 depicts a few contents for the Multimedia teaching and learning of Computer Networks which included instructional goals, concept description, routing algorithm, routing strategy, and problem visualisation.

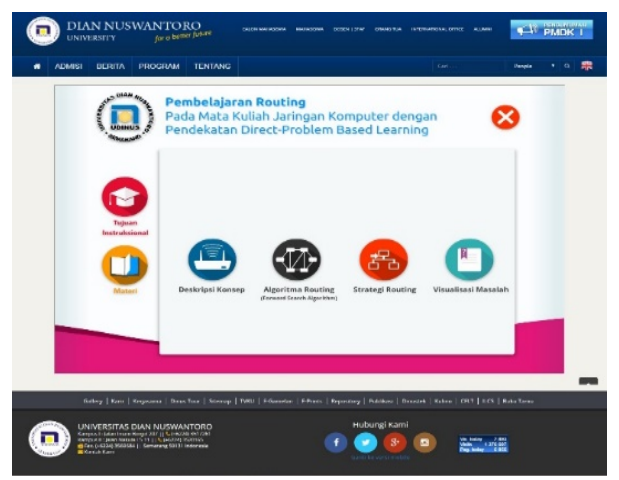

Fig. 1. Main menu of the multimedia teaching and learning for Computer Networks Subject

Fig.2 depicts the contents of routing such as concept description and routing algorithm. The concept description explained the routing, objectives, benefits, and types of routing. Meanwhile, the routing algorithm explained one of the routing algorithms, namely forward search algorithm. 
Fig. 3 depicts a few contents of routing such as routing strategy and problem visualisation. The strategy routing explained one of the routing strategies, namely flooding strategy. Meanwhile, the problem visualisation explained one of the problems in the routing process; for example, when one of the routers has an overload process.
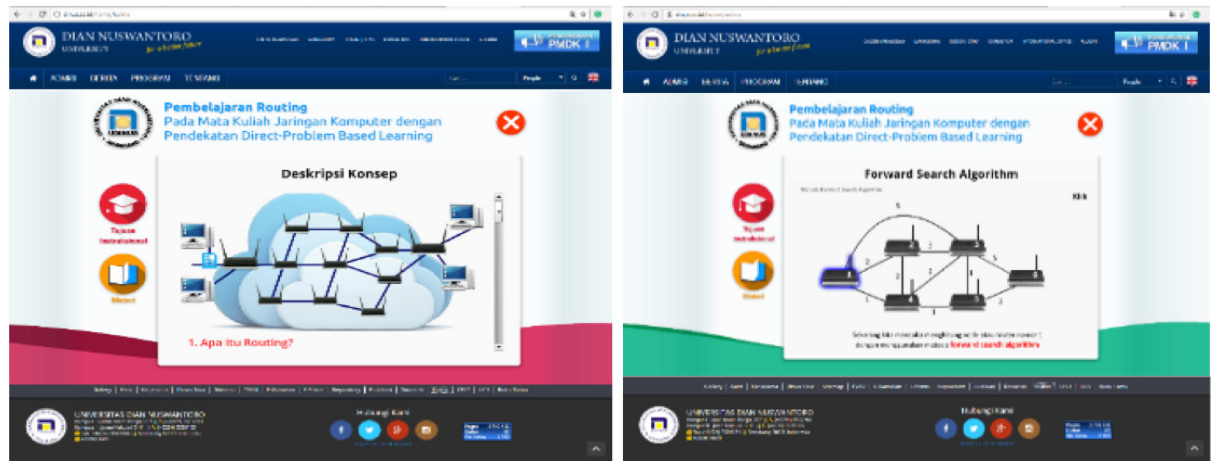

Fig. 2. Contents of concept description and routing algorithm menu

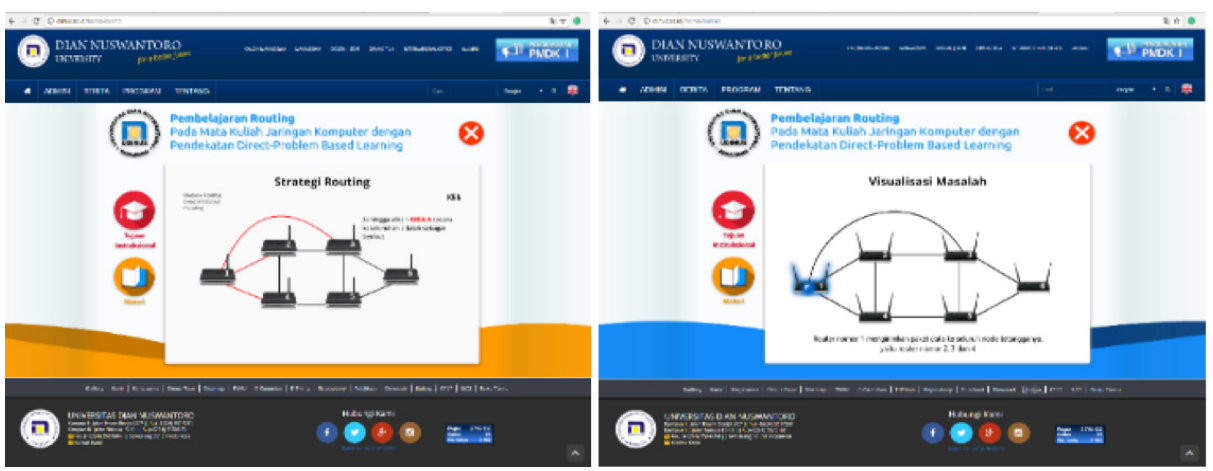

Fig. 3. Contents of routing strategy and problem visualisation

\section{$5 \quad$ Effectiveness}

The evaluation survey of learning activities using multimedia teaching and learning of Computer Networks in the DPBL approach (m-DPBL) was to determine the extent of m-DPBL impacts (i.e. students' knowledge, attitude, interest, and creative thinking, and teamwork skills). The survey result of the participants was summarised, namely the survey results from direct instruction (control group) and m-DPBL (experiment group). The demographics of the participants are as shown in Table 1.

Table 1 presents the comparison of the students' demographic in the direct instruction group versus m-DPBL group. The age was divided into two categories. Nearly all participants were aged below 20 years old. Meanwhile, the gender of the direct instruction group showed males to be $101(72.1 \%)$ and females $39(27.9 \%)$, while males were $92(67.6 \%)$ and females were $44(32.4 \%)$ for the m-DPBL group. Nearly all participants were male. 
Table 1. Demographic of students in the Control $(\mathrm{N}=140)$ and $\mathrm{m}-\mathrm{DPBL}(\mathrm{N}=136)$ groups.

\begin{tabular}{|c|l|c|c|}
\hline \multicolumn{2}{|c|}{ Demographic } & Control Group N(\%) & m-DPBL N(\%) \\
\hline \multirow{2}{*}{ Gender } & Male & $101(72.1)$ & $92(67.6)$ \\
\cline { 2 - 4 } & Female & $39(27.9)$ & $44(32.4)$ \\
\hline \multirow{2}{*}{ Age } & $18 \leq \mathrm{Age} \leq 20$ & $119(85)$ & $210(88.2)$ \\
\cline { 2 - 4 } & $21 \leq \mathrm{Age} \leq 26$ & $21(15)$ & $67(11.8)$ \\
\hline
\end{tabular}

Table 2 presents the comparison of the mean scores of the students in the direct instruction group versus m-DPBL group. There were mean score differences between the direct instruction and m-DPBL approaches (Figure 2). The mean score of the direct instruction group was $\overline{\boldsymbol{x}}(\boldsymbol{S} \boldsymbol{D})=25.39$ (2.78) in terms of attitude, $\overline{\boldsymbol{x}}(\boldsymbol{S} \boldsymbol{D})=28.82$ $(3,26)$ of interest, and $\overline{\boldsymbol{x}}(\boldsymbol{S} \boldsymbol{D})=32.06(7,69)$ of knowledge. Meanwhile, the m-DPBL group showed $\overline{\boldsymbol{x}}(\boldsymbol{S D})=27.54$ (3.17) for attitude, $\overline{\boldsymbol{x}}(\boldsymbol{S D})=30.16(3,57)$ for interest, and $\overline{\boldsymbol{x}}(\boldsymbol{S} \boldsymbol{D})=43.28(2,82)$ for knowledge.

Learning outcomes were significantly positively (Sig. $p=.000$ ) in terms of students' attitude, interest (Sig. $p=0.001$ ), and knowledge (Sig. $p=.000$ ). There were mean score differences between the direct instruction and m-DPBL approaches. The mean score of students' attitude increased 2.15 points $(7,8 \%)$, interest 1.34 points $(4,4 \%)$, and knowledge 11.22 points $(25,9 \%)$.

Table 2. The comparison of mean scores between groups based on attitude, interest, and knowledge variables

\begin{tabular}{|l|c|c|c|c|c|c|}
\hline \multirow{3}{*}{ Variables } & \multicolumn{2}{|c|}{ Frequencies } & \multicolumn{3}{c|}{ t-test for Equality of Means } \\
\cline { 2 - 7 } & $\begin{array}{c}\text { Control Group } \\
\overline{\boldsymbol{x}}(\boldsymbol{S D})\end{array}$ & $\begin{array}{c}\boldsymbol{M - D P B L} \text { Group } \\
\overline{\boldsymbol{x}}(\boldsymbol{S D})\end{array}$ & $\boldsymbol{t}$ & $\boldsymbol{d} \boldsymbol{f}$ & $\boldsymbol{p}$ & $\overline{\boldsymbol{x}}$ Difference \\
\hline Attitude & $25.39(2.78)$ & $27.54(3.17)$ & -5.999 & 274 & $.000^{*}$ & 2.15 \\
\hline Interest & $28.82(3.26)$ & $30.16(3.57)$ & -3.325 & 274 & $.001^{*}$ & 1.34 \\
\hline Knowledge & $32.06(7.69)$ & $43.28(2.28)$ & -16.19 & 274 & $.000^{*}$ & 11.22 \\
\hline
\end{tabular}

* Significant at $p<.05$

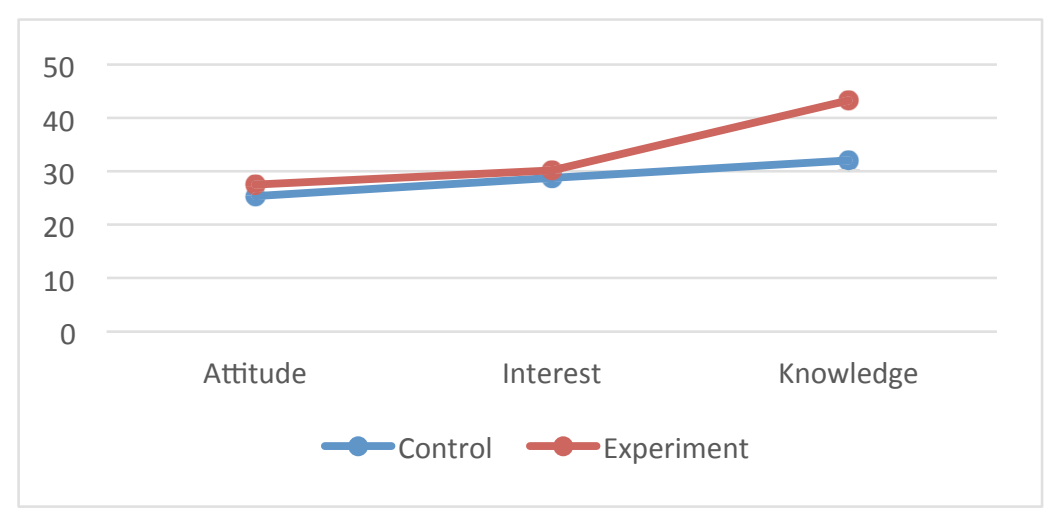

Fig. 4. Comparison of mean scores between groups based on attitude, interest, and knowledge variables 
Table 4 presents the comparison of mean scores of the creative thinking and teamwork skills in the direct instruction group versus m-DPBL group. There were mean score differences between direct instruction and m-DPBL approaches (Fig.4). The mean score of the direct instruction group was $\bar{x}=18.01$ in terms of creative thinking and $\bar{x}=21.61$ for teamwork. Meanwhile, for the m-DPBL group, the scores were $\overline{\boldsymbol{x}}=19.67$ for creative thinking skills and $\overline{\boldsymbol{x}}=24.42$ for teamwork skills. Students' creative thinking score increased 1.66 points $(8.4 \%)$, while their teamwork skills score increased 2.81 points $(11.5 \%)$.

Learning outcomes were significantly positive (Sig. $p=.000$ ). Thus, there was an indication that the m-DPBL approach benefited the students' creative thinking and teamwork skills.

Table 3. Comparison of mean scores of students' creative thinking and teamwork skills

\begin{tabular}{|l|c|c|c|c|c|c|}
\hline \multirow{2}{*}{ Variables } & \multicolumn{3}{|c|}{ Frequencies } & \multicolumn{4}{c|}{ t-test for Equality of Means } \\
\cline { 2 - 7 } & $\begin{array}{c}\text { Control Group } \\
\overline{\boldsymbol{x}}(\text { SD) }\end{array}$ & $\begin{array}{c}\boldsymbol{M - D P B L} \text { Group } \\
\overline{\boldsymbol{x}}(\text { SD) })\end{array}$ & $\boldsymbol{t}$ & $\boldsymbol{d f}$ & $\boldsymbol{p}$ & $\overline{\boldsymbol{x}}$ Difference \\
\hline Creative Thinking & $18.01(2.27)$ & $19.67(2.05)$ & -6.35 & 274 & $.000^{*}$ & 1.66 \\
\hline Teamwork & $21.61(3.55)$ & $24.42(2.32)$ & -7.77 & 274 & $.000^{*}$ & 2.81 \\
\hline
\end{tabular}

* Significant at $p<.05$

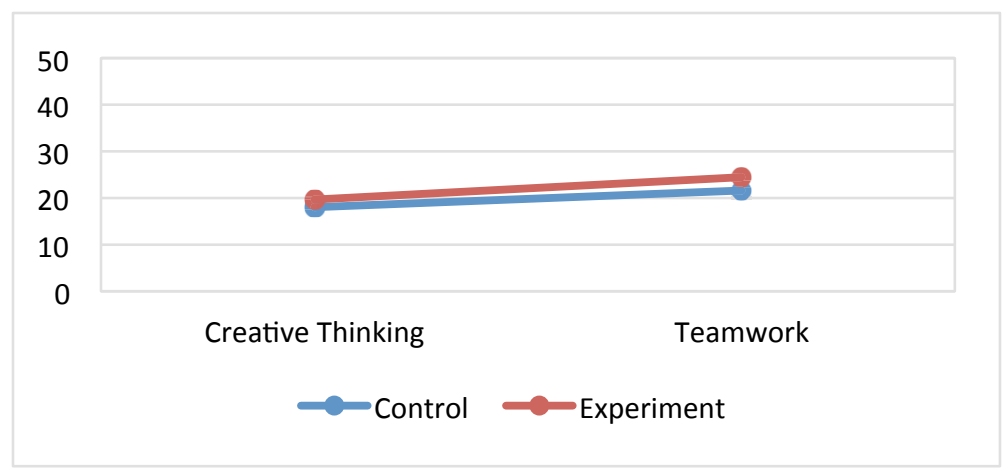

Fig. 5. Comparison of mean scores between groups based on the problem-solving skills variables

Table 4 presents the students' perception and effectiveness scorers, and feedback towards multimedia teaching and learning of Computer Networks in the DPBL approach (m-DPBL). Students' perception was at $\overline{\boldsymbol{x}}=36.88$ scores with 4.09 mean average score, while effectiveness was at $\bar{x}=40.02$ scores and 4.00 mean average score. Students' feedback showed $\overline{\boldsymbol{x}}=23.70$ for the mean score and 4.04 for the mean average score of useful feedback, $\overline{\boldsymbol{x}}=23.09$ for the mean score and 4.01 mean average score of content feedback, and $\bar{x}=20.39$ mean score and 4.08 mean average score of navigation feedback. 
Table 4. Feedback towards multimedia teaching and learning Computer Networks

\begin{tabular}{|l|c|c|c|c|c|}
\hline \multirow{2}{*}{ Descriptive Analysis } & \multicolumn{5}{|c|}{ Feedback } \\
\cline { 2 - 6 } & Perception & Effectiveness & Usefulness & Content & Navigation \\
\hline $\mathrm{N}$ & 136 & 136 & 136 & 136 & 136 \\
\hline$\overline{\boldsymbol{x}}$ & 36.88 & 40.02 & 23.70 & 23.09 & 20.39 \\
\hline Std. Deviation & 2.83 & 3.29 & 2.45 & 2.61 & 1.81 \\
\hline$\overline{\boldsymbol{x}}$ Average & 4.09 & 4.00 & 4.04 & 4.01 & 4.08 \\
\hline
\end{tabular}

Table 5 shows that the majority of the students had a positive response to the Learning Impact of the m-DPBL, with an average mean value $=4.09$, and the standard deviation of around .56. Students' feedback on the learning impact of the $\mathrm{m}$ DPBL approach indicated that the item of the listed questions showed a higher mean value $\bar{x}=4.12$ with low standard deviation value $=.505$.

Table 5. Learning impacts using $\mathrm{m}-\mathrm{DPBL}$ approach

\begin{tabular}{|l|c|c|}
\hline \multirow{2}{*}{\multicolumn{1}{|c|}{ Questions List }} & \multicolumn{2}{c|}{ Results (N=136) } \\
\cline { 2 - 3 } & $\overline{\boldsymbol{x}}$ & $\begin{array}{c}\text { Std. } \text { Devia- } \\
\text { tion }\end{array}$ \\
\hline I am motivated to learn Computer Networks in the m-DPBL learning situation. & 4.07 & .611 \\
\hline m-DPBL is effective method than conventional teaching of Computer Networks & 4.10 & .643 \\
\hline m-DPBL has positive impact on my leaning of Computer Networks & 4.12 & .517 \\
\hline My communication skills were increased by m-DPBL & 4.07 & .505 \\
\hline My teamwork skills were increased by m-DPBL & 4.10 & .543 \\
\hline Summary & 4.09 & .564 \\
\hline
\end{tabular}

\section{Conclusion}

Multimedia in the Direct Problem-Based Learning (m-DPBL) approach for Computer Networks teaching and learning was designed especially to improve students' attitude, interest, and knowledge, and problem-solving skills (i.e. students' creative thinking and teamwork skills).

Learning outcomes were significantly positive in terms of students' attitude, interest, and knowledge. There were mean score differences between the direct instruction and m-DPBL approaches. Students' attitude mean score increased 2.15 points $(7,8 \%)$, students' interest mean score increased 1.44 points $(4,4 \%)$, and students' knowledge mean score increased 11.22 points $(25,9 \%)$.

Nearly all participants had a positive response to the m-DPBL strategy. The students' attitude, interest, knowledge, and creative thinking and teamwork skills were increased. Therefore, the m-DPBL approach was suggested as an instructional approach for the teaching process. 


\section{$7 \quad$ Acknowledgement}

This research was supported by Dian Nuswantoro University. The authors gratefully acknowledge the research assistance provided by Dian Nuswantoro University, Indonesia.

\section{$8 \quad$ References}

[1] Tan, O.S, Teo, C.T., \& Chye, S. Problem-Based Learning and Creativity. OonSeng Tan (Ed.) Cengage Learning Asia Pte. Ltd., Singapore, 2009, pp.1-14.

[2] Vinay, M., \& Rassak, S. A Technological Framework for Teaching-Learning Process of Computer Networks to Increase the Learning Habit. International Journal of Computer Application (0975-8887), 2015, Vol 117-No.4.

[3] Choi, E., Lindquist, R., \& Song, Y. Effect of Problem-Based Learning vs. Traditional lecture on Korean nursing students' critical thinking, problem-solving, and self-directed learning." Nurse Education Today, 2014, vol.34, pp. 52-56. https://doi.org/10.1016/j.nedt. 2013.02.012

[4] Vaughan, T. Multimedia: Making it Work ( $4^{\text {th }}$ Ed.), Berkeley, CA: Osborne/McGraw-Hill, 1998.

[5] Neo, M., \& Neo, K.T.K. Innovative teaching: Using multimedia in a problem-based learning environment. Educational Technology \& Society 4 (4), 2001, ISSN 1436-4522.

[6] Chang, R. Teaching computer networking with the help of personal computer networks. ITiCSE'04, June 28-30, Leeds, United Kingdom, 2004.

[7] Armani, J., Botturi, L., Cantoni, I., Benedetto, M.D., \& Garzotto, F. Integrating Instructional Design and Hypermedia Design, In L. Cantoni \& C. McLoughlin (Eds.). Proceedings of World Conference on Educational Multimedia, Hypermedia and Telecommunications. (pp. 1713-1719). Chesapeake, 2004, VA: AACE.

\section{Authors}

Sri Winarno is with Dian Nuswantoro University, Faculty of Computer Science, Semarang City 50131, Indonesia

Kalaiarasi Sonai Muthu and Lew Sook Ling are with Multimedia Universtiy, Faculty of Information Science and Technology, Melaka 75450, Indonesia.

Article submitted 07 November 2017. Resubmitted 23 January 2018. Final acceptance 23 February 2018. Final version published as submitted by the authors. 